\title{
Classroom quality and student engagement: contributions to third-grade reading skills
}

\author{
Ying Guo ${ }^{1 *}$, Carol McDonald Connor ${ }^{2}$, Virginia Tompkins ${ }^{3}$ and Frederick J. Morrison ${ }^{4}$ \\ I School of Education, University of Cincinnati, Cincinnati, OH, USA \\ 2 Department of Psychology, Florida Center for Reading Research, Florida State University, Tallahassee, FL, USA \\ ${ }^{3}$ Department of Psychology, The Ohio State University at Lima, Lima, OH, USA \\ ${ }^{4}$ Combined Program in Education and Psychology, University of Michigan, Ann Arbor, MI, USA
}

\section{Edited by:}

Weihua Fan, University of Houston, USA

\section{Reviewed by:}

Cassandra Shular Coddington

University of Alabama, USA

Jessica J. Summers, University of

Arizona, USA

\section{*Correspondence:}

Ying Guo, School of Education,

University of Cincinnati, Teachers/Dyer

Hall, Cincinnati, OH 45221, USA

e-mail:yguo@ehe.osu.edu

\begin{abstract}
This study, using NICHD Study of Early Child Care and Youth Development longitudinal data, investigated the effects of classroom quality and students' third-grade behavioral engagement on students' third-grade reading achievement $(n=1,364)$ and also examined the extent to which students' third-grade behavioral engagement mediated the association between classroom quality and children's reading skills. SEM results revealed that controlling for family socio economic risk and students' first-grade reading achievement, classroom quality significantly, and positively predicted children's behavioral engagement, which in turn predicted greater reading achievement. Higher levels of children's behavioral engagement were associated with higher reading achievement. Implications for policy and practice are discussed.
\end{abstract}

Keywords: classroom quality, student engagement, reading achievement

\section{INTRODUCTION}

A number of empirical findings have supported the importance of students' reading skills, but too many children fail to achieve reading proficiency by fourth grade [National Assessment of Educational Progress (NAEP), 2007; Snow, 2001]. In fact, early delays in reading skills are associated with later attention and behavior problems and higher rates of referral to special education (Adams and Snowling, 2001; National Assessment for Education Progress, 2005; Maughan and Carroll, 2006).

Not surprisingly, considerable attention has focused on ways to facilitate children's reading development. Over the last decade, researchers have identified the features of children's dynamic experience in the classroom that appear particularly influential to children's reading development and these include classroom quality, conceptualized as daily interactions between teachers and children (e.g., NICHD-ECCRN, 2002; Connor et al., 2005; Hamre and Pianta, 2005; Mashburn et al., 2008; Pianta and Hamre, 2009) as well as children's engagement in activities, defined as the extent to which children attend to learning tasks (Kumar, 1991; Ponitz et al., 2009). For the most part, research on the reading development of children has focused on the influence of classroom quality, with less attention focused on children's engagement. In the present study, controlling for family social economic status (SES) and prior reading skills, we examined the unique contributions of classroom quality and children's engagement to children's reading achievement as well as whether the relation between classroom quality and children's reading skills was mediated by children's engagement, with a particular focus on third-grade students.

\section{THEORETICAL FRAMEWORK}

Currently, empirical findings of children's reading development indicate that reading achievement is multiply determined, predicted by such multiple interrelated factors as children's developmental characteristics (e.g., age, attention, and behavior), home environment, and classroom quality (e.g., Rayner et al., 2001; Connor et al., 2005; Petrill et al., 2007). Thus, ecological effects are important to understanding children's reading development. As such, our study was guided by an ecological developmental approach.

Bronfenbrenner and Morris (2006) contended that an ecological developmental approach is served by the four constructs triggering growth and change in academic competence, namely person, process, context, and time. The present study focused on three constructs: person, process, and context, all of which directly influence children's development. Person indicates child characteristics such as prior reading skills and family SES. Process represents the activities or interactions in which children are engaged in. Context indicates the environment and its associated learning opportunities (Ponitz et al., 2009). In this study, children's engagement represented process; classroom quality (quality of teacher-child interactions) was used as an indicator of context and children's SES and prior literacy skills were used as indicators of person. Time is captured indirectly by the longitudinal design of the study.

The ecological developmental approach emphasizes the importance of interrelationships among person, process, and context when studying children's development. Rather than examining individual contributions of each construct, the ecological framework suggests that researchers also attend to the interactive effects among these constructs (Bronfenbrenner, 1979). In fact, researchers have attempted to examine the interactive process between process and context in predicting children's learning. Specifically, context (teacher-child interactions) promotes child achievement indirectly through positive association with process (children's engagement; e.g., Guthrie et al., 2001; Greenwood et al., 2002; Perry et al., 2002; Ponitz et al., 2009). In the current study, we aimed to expand the existing literature by examining the individual influences of process (children's engagement) and context (teacher-child interactions) 
and how they interact. We also controlled for key person variables: children's SES and prior literacy skills. A brief review of classroom quality and children's engagement associated with child achievement follows.

\section{CLASSROOM OUALITY, CHILDREN'S ACHIEVEMENT, AND ENGAGEMENT}

The global quality of classroom is typically differentiated in terms of structural (i.e., teacher education; group sizes) versus process features (teacher-child interactions; Mashburn et al., 2008). In the present study, we restrict our focus on process features - teacherchild interactions most proximal to child learning. Teacher-child interactions indicate how teachers and students talk together, listen to each other, and generally interact verbally and non-verbally. These interactions, which take place on a daily basis, are thought to be the primary mechanism through which children learn (Hamre and Pianta, 2005, 2007; Mashburn et al., 2008). Two broad dimensions of teacher-child interactions emerge: teachers' emotional support and instructional support, both of which have been linked to children's development theoretically and empirically. In general, emotional support encompasses the teachers' sensitivity and responsiveness toward specific children, emotional warmth, and negativity (NICHD-ECCRN, 2002; Pianta et al., 2008a). Theories of motivation suggest that sensitive, responsive, and positive interactions between teachers and children could make children perceive teachers as more supportive and hence children are more motivated to learn (Deci and Ryan, 1985; Connell and Wellborn, 1991; Eccles, 1993). Likewise, children who have more motivation to learn generally show stronger academic achievement (Roeser et al., 2000; Gregory and Weinstein, 2004). Empirical evidence has suggested that teachers' emotional support is a potentially important factor for predicting children's reading growth over time (e.g., NICHDECCRN, 2000; Rivik et al., 2000; Pianta et al., 2002; Connor et al., 2005).

Teachers' instructional support refers to teacher's use of the classroom activities to effectively support children's academic development (Hamre and Pianta, 2005; Pianta et al., 2008b). The classrooms with higher levels of instructional support are characterized by frequent conversations, modeling of conceptual thinking, frequent feedback loops, and explicit discussion of language and literacy (e.g., Taylor et al., 1986; Snow et al., 1998; Makin, 2003; Meehan et al., 2003; Hamre and Pianta, 2005; Justice et al., 2008; Pianta and Hamre, 2009). These instructional inputs are important contributors to children's literacy achievement (e.g., NICHDECCRN, 2000; Justice et al., 2008).

In addition to the relation between classroom quality as indexed by teacher-child interactions and students' skills, several studies have reported a link between teacher-child interactions and children's engagement (Ryan and Patrick, 2001; Assor et al., 2002; Hughes and Kwok, 2007). For instance, Ryan and Patrick (2001) found that the social environment of eighth-grade classrooms was significantly associated with changes in engagement when students moved from seventh to eighth grade. Hughes and Kwok (2007) recently also reported that the quality of teacherchild interactions was positively correlated with first-grade children's engagement. The documented relationship between teacher-child interactions and higher level of child engagement was not unexpected. Many researchers propose that children who receive high-quality support from teachers are more engaged in that they study harder, attend more to teachers, and confirm to classroom rules and routines (e.g., Wentzel, 1999; Ridley et al., 2000; Little and Kobak, 2003).

\section{CHILDREN'S ENGAGEMENT AND CHILDREN'S ACHIEVEMENT}

Researchers have operationalized engagement as a multidimensional concept in terms of behavioral, cognitive, and motivational engagement (Linnenbrink and Pintrich, 2003). Given that many studies supported the significant association between behavioral engagement and academic achievement for elementary, middle, and high school students (e.g., Skinner et al., 1990; Marks, 2000), this study conceptualized engagement as observable behavior. Although behavior engagement has been defined differently by different studies, most often behavioral engagement has been defined as involvement in learning activities and includes behaviors such as attention, persistence, and concentration (e.g., Birch and Ladd, 1997; Fredericks et al., 2004). Among these behaviors, attention which represents the extent to which children are observed to attend to learning activities, appeared to be critically important in promoting children's learning as a consistent, significant relationship was reported between the level of attention and children's reading or math achievement (e.g., Peterson et al., 1984; Wasson et al., 1990). In addition, recent research has placed an emphasis on another child behavior related to engagement - self-reliance, which "reflects the degree to which the child displays autonomy, self-regulation, and personal initiative in the classroom" (Rimm-Kaufman et al., 2002, p. 459). Children who are self-reliant are more likely to exhibit behavior that promotes learning and demonstrate more reading skills (Rimm-Kaufman et al., 2002; Ponitz et al., 2009). Thus, the current study used the level of children's attention and self-reliance to represent the construct of children's engagement.

Educational researchers have suggested that, compared with those who are not engaged, engaged children "are thought to be more intensively and extensively involved - behaviorally, intellectually, and emotionally - in their learning" (Bangert-Drowns and Pyke, 2001, p. 23). From this perspective, children's engagement contributes to their social and cognitive achievement (Newmann, 1992). In fact, the importance of student engagement is supported in empirical work. For example, Singh et al. (2002) found that eighth-grade students' engagement, defined as academic time spent in math and science, was a strong predictor of their math and science achievement. In terms of reading skills, Campbell et al. (1997) reported a significant association between engagement and reading achievement in a national sample of elementary school students. Wigfield et al. (2008) also found a significant association between fourth-grade students' reading engagement and their reading achievement. Similarly, middle school students with higher level of reading engagement had higher reading achievement than those students who were lowly engaged (Guthrie and Wigfield, 2000). The studies referenced above have supported the view that engaged learners are motivated to use cognitive strategies and interact in a classroom community (Guthrie, 1996). These behaviors that children displayed are all associated with their achievement.

The importance of children's engagement in reading achievement reflects social-interactionist theories of how children acquire reading. Social-interactionist theories view reading acquisition as 
occurring within the "social context of discourse, in the miniaturized culture that governs the communicative interaction of children and adults" (Bruner, 1981, p. 175). Such a perspective stresses the role of child's active involvement in the literacy acquisition process in fostering growth.

\section{MEDIATING ROLE OF CHILDREN'S ENGAGEMENT}

Although in the previous sections we have considered classroom quality and children's engagement separately, it is possible that children's engagement may mediate or interact with the quality of teacher instruction in the classroom to impact achievement (Guthrie et al., 2001; Greenwood et al., 2002; Perry et al., 2002; Ponitz et al., 2009). By way of illustration, consider a case in which children have difficulty in being engaged in learning. In such instances, teachers might interact with them in sensitive, responsive, and positive ways. Such children would be more likely to feel more support from teachers and hence be more engaged in learning. High levels of children's engagement may improve their academic achievement. Therefore, social interactions with teachers within the school setting may serve as a protective factor for children who are weakly engaged in learning.

In fact, some empirical studies have shown that children's engagement mediated the effects of classroom instruction on children's reading skills (e.g., Wigfield et al., 2008; Ponitz et al., 2009). For example, Ponitz et al. (2009) found that kindergartener's behavior engagement significantly mediated the relation between classroom quality and their reading achievement. Wigfield et al. (2008) also found that reading instruction improved fourth-grade children's reading achievement through increasing engaged reading. Such findings are important because they help explain how classroom quality increased children's reading skills and highlighted the importance of children's engagement. However, to our knowledge, only these two studies have attempted to determine whether the effects of classroom quality on children's learning were attributable to children's engagement in instruction. Therefore, the primary focus of the present study was to examine to what extent the effects of classroom quality on children's reading skills were mediated by the children's level of engagement. The current study focused on third-grade children because academic achievement during middle childhood (from Grade 1 to Grade 5) is critical to a successful developmental trajectory through this period and into adolescent (Eccles et al., 2006). Furthermore, much of high-stakes accountability assessment starts in third grade (Pianta et al., 2008a). It seems imperative to understand the underlying mechanism of classroom quality and children's engagement contributing to reading achievement in third grade.

\section{STUDY PURPOSE AND RESEARCH QUESTIONS}

The findings reviewed above provide evidence of a growing body of literature suggesting the importance of both classroom quality and children's engagement as sources of influence on student achievement. In the present study, our goal was to examine the relations among children's engagement, classroom quality, and students' third-grade reading, controlling for family SES, and students' Grade 1 reading ability. Our conceptual model (see Figure 1) allows us to examine the influences of classroom quality and student

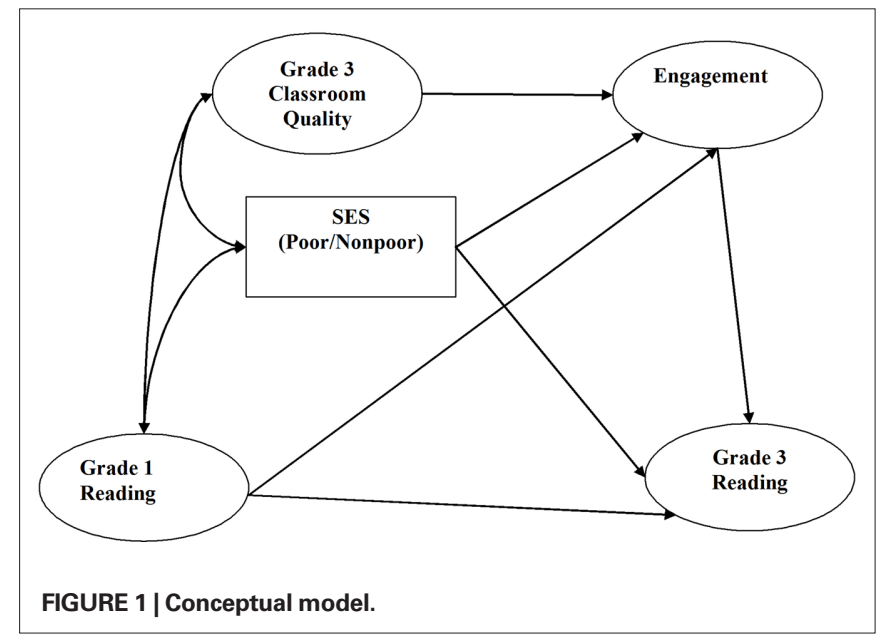

engagement simultaneously, while investigating the unique contribution of each to students' reading skills. Specially, we asked three research questions to guide our investigations:

(1) Are the effects of classroom quality on students' third-grade reading outcomes mediated through students' third-grade engagement? We hypothesized that classroom quality affected child reading outcome via child engagement.

(2) What is the mediated effect of classroom quality on student reading outcomes? We tested the indirect path from classroom quality to child reading outcomes via child engagement. And what are the direct effects of classroom quality on child engagement and child reading outcomes? We tested the two direct paths: one from classroom quality to child engagement and the other one from classroom quality to child reading outcomes.

(3) What is the direct effect of child engagement on child reading outcomes? We tested the direct path from child engagement to child reading outcomes.

\section{MATERIALS AND METHODS PARTICIPANTS}

Children included in this study took part in the Phase III study of the larger ongoing longitudinal NICHD Study of Early Child Care and Youth Development (SECCYD; please see http://secc.rti. org/for additional information about the NICHD study). Children participating in NICHD SECCYD are followed and their developments are assessed at frequent intervals from birth through adolescence.

Of the students and classrooms, the present study included 1,364 students and their teachers. Given that NICHD SECCYD is a longitudinal study, some students and their teachers did not provide complete data on all variables in this study. We used the full information maximum likelihood method in AMOS 18.0 (Arbuckle, 2006) to deal with the missing data. Of all the participants, $24 \%$ of the children were ethnic minority group and $11 \%$ of the mothers had less than a high school education. Mean family income was 3.6 times the poverty threshold. Almost half of the children were male (49\%). The children participating in NICHD SECCYD came from 10 locations in the United States (Little Rock, AR; Irvine, CA; Lawrence, KS; Boston, MA; Philadelphia, PA; Pittsburgh, PA; Charlottesville, VA; 
Morganton, NC; Seattle, WA; and Madison, WI). For each classroom, only one child was selected to participate in study. If more than one child within the same classroom participating in the study, one child was randomly selected for classroom-level data analysis.

\section{MEASURES}

\section{Children's family SES}

Mothers participating in NICHD SECCYD were required to report household income during interviews conducted in person or on the phone at the repeated intervals throughout the birth to thirdgrade period. The household incomes were divided by the federal standard for household poverty to obtain an income-to-needs ratio at each occasion. For the present inquiry, we averaged incometo-needs ratio from the 54-month to the third-grade period and derived an index of financial resources. Using similar procedures as Pianta et al. (2008a), we sorted the averaged index into two categories representing the variables of less than or equal to 2 (poor) and above 2 (non-poor). As a result, the dichotomous variable (poor/non-poor) was used in our analysis; having a mean of 0.78 and ranging from 0 to 1 (see Table $\mathbf{1}$ ).

\section{Classroom quality}

The present study used the classroom observation system for third grade (COS-3), developed specifically for the NICHD SECCYD to evaluate teachers' and children's behavior and classroom environment. The observation was coded for the quality of interaction between teacher and the specific children enrolled in study and the activities that children were engaged in. Details of coding procedures are provided in the manual (see http://secc.rti.org).

Classroom observation system for third grade included the global quality of ratings of teacher-child interactions. Coders observed and provided global ratings of teachers' interactions with the study child before and at the end of each time-sampling period. Each rating is presented as a 7 -point rating scale ( $1=$ uncharacteristic to $7=$ extremely characteristic).

In the current study, we used two variables to represent the construct of classroom quality (latent variable indicated by emotional support and instructional support). Specifically, we used the factor-based

Table 1 | Descriptive statistics for all the variables.

\begin{tabular}{lccc}
\hline Measures & Mean & SD & Range \\
\hline $\begin{array}{l}\text { SES (poor/non-poor) } \\
\text { Grade 3 teacher }\end{array}$ & 0.77 & 0.42 & $0-1$ \\
emotional support & 5.73 & 0.62 & $2.85-6.98$ \\
Grade 3 teacher & & & \\
instructional support & 3.49 & 0.69 & $1.31-6.19$ \\
Grade 3 attention & & & \\
Grade 3 self-reliance & 4.76 & 0.97 & $2-7$ \\
Grade 1 letter-word & 4.37 & 0.98 & $1.13-7$ \\
Grade 1 picture vocabulary & 452.96 & 24.12 & $356-520$ \\
Grade 1 word attack & 484.58 & 12.67 & $434-519$ \\
Grade 3 letter-word & 473.94 & 17.73 & $436-517$ \\
Grade 3 vocabulary & 493.86 & 18.73 & $367-536$ \\
Grade 3 passage & 496.94 & 11.51 & $440-531$ \\
comprehension & 495.29 & 14.53 & $404-527$ \\
& & &
\end{tabular}

composite emotional support, which included the scales of positive emotional climate, teacher sensitivity, overcontrol-reversed, chaosreversed, and negative climate-reversed, similar to the study of Pianta et al. (2008a). Positive emotional climate reflected pleasant conversations, spontaneous laughter, and positive warmth and regards provided by teachers. By contrast, sensitivity indicated manifest awareness of the children's academic and social needs, and responsiveness to distress. Overcontrol described that a rigidly structured classroom are controlled by teachers without the room for autonomy. Chaos was marked by lack of effective behavior management and disorganization. Negative climate reflected hostile, angry, punitive, and controlling interactions. The score of emotional support is the averaged scores of these five scales that have been described above. The mean of Grade 3 teachers' emotional support was 5.75 ( $S D=0.60$, see Table 1), reflecting emotional support at the high end of middle-range.

We also used the factor-based composite of instructional support, which included the scales of productive use of time and richness of instructional methods, similar to the study of Pianta et al. (2008a). Productive use of instructional time indicated brief and efficient transitions among different activities and consistent provision of learning activities within transitions. Richness of instructional method was marked by the quality and quantity of instructional discussions and activities that teachers provided to promote children's development. The score of instructional support is the averaged scores of the two scales that have been discussed above. The mean of Grade 3 teachers' instructional support was 3.49 ( $\mathrm{SD}=0.69$, see Table 1$)$, reflecting instructional support at the low end of middle-range.

With respect to reliability of COS-3, all observers achieved at least $60 \%$ coding reliability with the videotaped reliability test involving six 440 min cycles involving global rating. NICHD-ECCRN (2003) reported that average reliability for the teacher global rating on the videotaped test was 0.63. Additionally, Pianta et al. (2008a) selected 52 classrooms among those enrolled in NICHD SECCYD to examine the relation between codes for classrooms observed more than once. This study reported that the averaged cross-day correlation for the qualitative rating in third-grade observation was 0.91 .

\section{Children's engagement}

For this study, the global rating of children's behavior in COS-3 was used to assess the level of children's engagement. Children's behaviors were rated on a 7-point Likert-type scale ( 1 = uncharacteristic to $7=$ extremely characteristic). The current study selected the global ratings of two child behaviors, namely attention (the extent to which the child attended to the learning activities) and self-reliance (the extent to which the child demonstrated initiative, focus, autonomy, and leadership) to represent the latent variable of children's engagement. The mean rating of child attention was 4.79 , ranging from 2 to 7 ; the mean rating of child self-reliance was 4.43 , ranging from 1.25 to 7 (see Table 1 ).

\section{Grade 1 reading skills}

Children's first-grade reading skills were measured using letterword identification, picture vocabulary, and word attack subtests of the Woodcock Johnson Psychoeducational Battery-Revised (WJ-R; Woodcock and Johnson, 1989/1990). Letter-word identification assessed children's word identification and recognition skills. Picture vocabulary measured children's ability to name objects 
depicted in a series of pictures. Word attack assessed children's phonological decoding. For the statistical analysis, $\mathrm{W}$ scores which were centered on a value of 500 were used, which are a "special transformation of the Rasch ability scale" (Woodcock and Mather, 2001, p. 72). See Table 1 for descriptive information on children's first-grade letter-word identification, picture vocabulary, and word attack subtests.

\section{Grade 3 reading skills}

Children's reading achievement in Grade 3 was indicated by three subtests of WJ-R, namely letter-word identification, picture vocabulary, and passage comprehension which assessed the children's comprehension skills. For the statistical analysis, W scores were also used for all three subtests. See Table 1 for descriptive information on letter-word identification, picture vocabulary, and passage comprehension subtests when children were in Grade 3.

\section{ANALYTIC APPROACHES}

Structural equation modeling (SEM) was used as our data analytic strategy. We employed several criteria to assess the fit for our model including $x^{2}$ which is ideally non-significant, indicating a good fit of the model. However, the value of $x^{2}$ was sensitive to large sample size (Marsh, 1994). Thus other statistics were also used to assess the model fit including the Tucker Lewis index (TLI), comparative fit index (CFI), and the root mean squared error of approximation (RMSEA).A cut-off value of TLI and CFI should be 0.90 or greater, indicating a close fit (Hu and Bentler, 1999). The value of RMSEA should be around 0.05, representing a close fit (Brown and Cudeck, 1993). Last, the Sobel test (Preacher and Leonardelli, 2001) was used to test whether indirect effects were significant or not because the Sobel test was considered as the strongest compared with other 14 methods for testing mediation effects (MacKinnon et al., 2002).

\section{RESULTS}

Prior to addressing the main research purposes, the correlations among all the variables were examined. As shown in Table 2, Grade 3 teacher emotional support was significantly and positively correlated with children's third-grade attention, self-reliance, and reading achievement. Similarly, Grade 3 teacher instructional support was also positively associated with children's third-grade attention, self-reliance, and reading achievement. Significant intercorrelations among children's third-grade attention and self-reliance, Grade 1 reading skills, and Grade 3 reading skills were also found in the current study.

\section{ARE THE EFFECTS OF CLASSROOM QUALITY ON STUDENTS' THIRD- GRADE READING OUTCOMES MEDIATED THROUGH STUDENTS' THIRD-GRADE ENGAGEMENT?}

We hypothesized that classroom quality would impact children's reading outcomes indirectly through children's engagement. We tested this hypothesis first by comparing two models. The first model did not include direct paths from Grade 3 classroom quality to students' reading achievement when they are in Grade 3 (see Figure 2). The second model included the direct paths from Grade 3 classroom quality to students' reading achievement when they are in Grade 3. Both models fit the data reasonably well. The first model represented in Figure 2 has a $x^{2}$ of $284.22, \mathrm{df}=34, \mathrm{CFI}=0.96$, $\mathrm{TLI}=0.92$, and RMSEA $=0.07$. The second model has $x^{2}$ of 281.61, $\mathrm{df}=33$, CFI $=0.96$, TLI $=0.92$, and RMSEA $=0.07$. As the first model was nested within the second model, we thus compared their relative fit by performing a $x^{2}$ difference test. Results showed that the first model did not fit significantly worse than the second model ( $x^{2}$ difference $\left.=2.56, \mathrm{df}=1, p=0.11\right)$, suggesting classroom quality indirectly impacted student reading outcomes when they were in Grade 3. The first model represented in Figure 2 was used in the present study. Parameter estimates for both models are summarized in Table 3. The path model (the first model) is provided in Figure 2. In both instances, children's SES was a significant predictor of third grade engagement and reading outcomes. First-grade reading skills significantly predicted third-grade engagement and reading skills.

\section{WHAT IS THE MEDIATED EFFECT OF CLASSROOM QUALITY ON STUDENT READING OUTCOMES? AND WHAT ARE THE DIRECT EFFECTS OF CLASSROOM QUALITY ON CHILD ENGAGEMENT AND CHILD READING OUTCOMES?}

First, we examined the mediated effect of Grade 3 classroom quality through Grade 3 children's engagement as they affect the reading skills of third-graders (classroom quality $\rightarrow$ children's engagement $\rightarrow$ children's reading outcomes). Sobel test results

Table 2 | Intercorrelations among all the variables.

\begin{tabular}{|c|c|c|c|c|c|c|c|c|c|c|c|}
\hline & 1 & 2 & 3 & 4 & 5 & 6 & 7 & 8 & 9 & 10 & 11 \\
\hline SES (poor/non-poor) & - & $0.11^{* *}$ & $0.11 * *$ & $0.13^{* *}$ & $0.20 * *$ & $0.268^{*}$ & $0.29 * *$ & $0.26^{* *}$ & $0.33^{* *}$ & $0.33^{* *}$ & $0.32^{* *}$ \\
\hline Grade 3 teacher emotional support & & - & $0.55^{* *}$ & $0.31 * *$ & $0.32 * *$ & $0.09 * *$ & $0.17 * *$ & $0.13^{* *}$ & $0.15^{* *}$ & $0.17^{* *}$ & $0.17 * *$ \\
\hline Grade 3 attention & & & & - & $0.79 * *$ & $0.15^{* *}$ & $0.12 * *$ & $0.15^{* *}$ & $0.20 * *$ & $0.15^{* *}$ & $0.21 * *$ \\
\hline Grade 3 self-reliance & & & & & - & $0.26 * *$ & $0.20^{* *}$ & $0.23^{* *}$ & $0.29 * *$ & $0.24^{* *}$ & $0.30 * *$ \\
\hline Grade 1 word attack & & & & & & & & - & $0.72 * *$ & $0.44^{* *}$ & $0.63 * *$ \\
\hline Grade 3 letter-word & & & & & & & & & - & $0.57^{* *}$ & $0.80^{* *}$ \\
\hline Grade 3 vocabulary & & & & & & & & & & - & $0.65^{* *}$ \\
\hline Grade 3 passage comprehension & & & & & & & & & & & - \\
\hline
\end{tabular}

${ }^{* *} p<0.01$ 


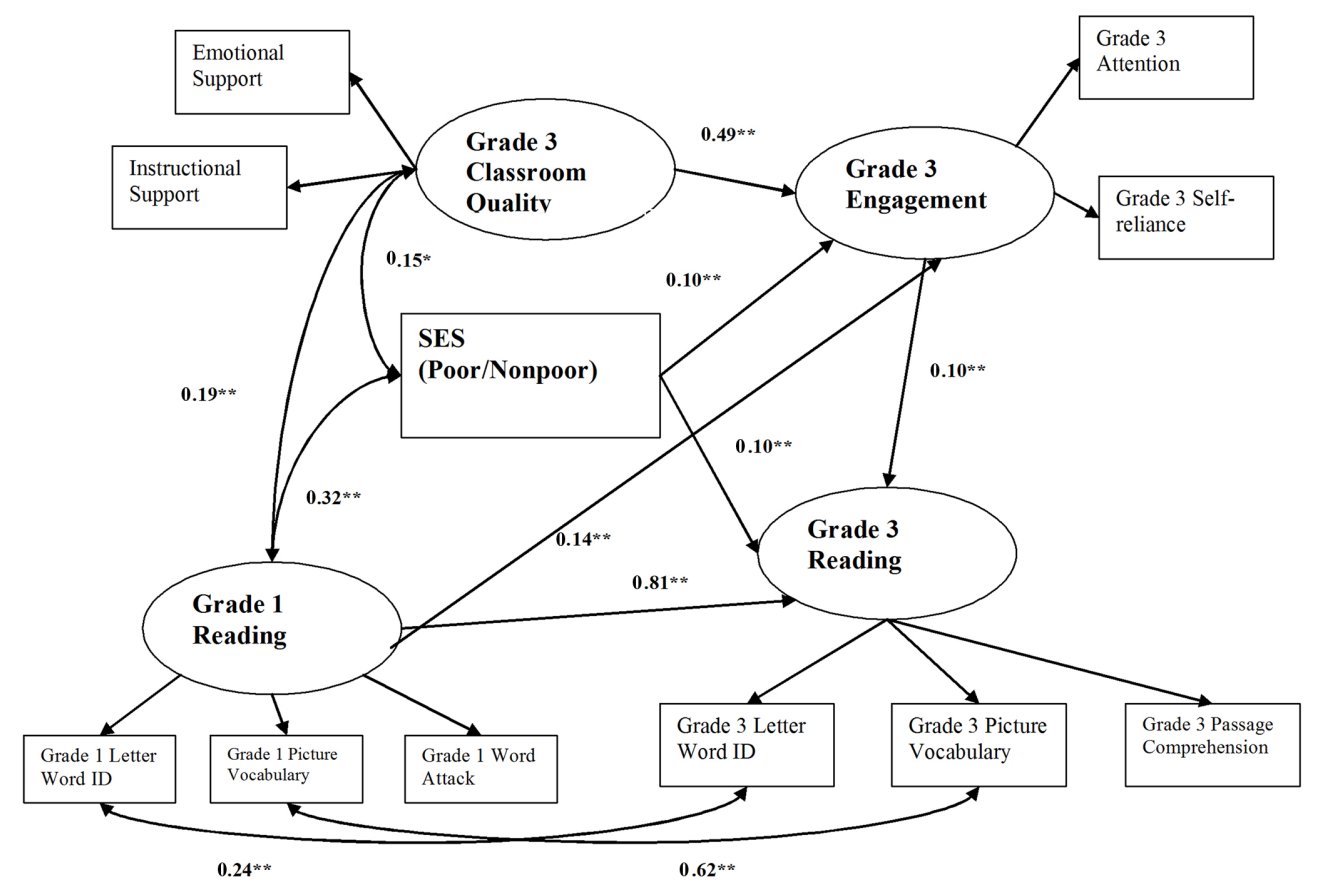

FIGURE 2 | Final model. Standardized path coefficients are provided for each path that reached $95 \%$ confidence levels (see Table 3). All endogenous variables have error terms.

demonstrated that the indirect effect from classroom quality to children's reading achievement via children's engagement was significant (unstandardized path coefficient $=0.79, p<0.001$ ). Multiplying the two relevant paths (see Figure 2) provided the size of the indirect effect of classroom quality on Grade 3 reading skills via children's engagement: $0.49 \times 0.10=0.05$.

Second, we examined the direct effect of Grade 3 classroom quality on children's engagement. As the direct path of Grade 3 classroom quality to Grade 3 reading achievement is not significant, we did not report the direct effect of Grade 3 classroom quality on children's reading achievement. Our results showed that classrooms with high-quality had children who were more engaged (standardized path coefficient $=0.49, p<0.01$, see Table 3 and Figure 2), after controlling for children's SES and their reading skills when they are in Grade 1.

\section{WHAT IS THE DIRECT EFFECT OF CHILD ENGAGEMENT ON CHILD READING OUTCOMES?}

We found that Grade 3 engagement was a significant predictor of their reading achievement (standardized path coefficient $=0.10$, $p<0.001$, see Table 3 and Figure 2), after controlling for children's SES and their reading skills when they are in Grade 1. This result indicated that students who were more engaged tended to demonstrate higher reading skills. In addition, we also found evidence concerning the reciprocal relation between children's engagement and their reading skills. As shown in Table 3 and Figure 2, Grade 1 reading skill significantly and directly predicted Grade 3 engagement ( standardized path coefficient $=0.14$, $p<0.001)$.

\section{DISCUSSION}

Our findings confirm the ecological perspective that informed the investigation (Bronfenbrenner and Morris, 2006). As expected, three major findings emerged from this study. First, our findings indicated that high level of classroom quality operated indirectly through children's engagement to predict their reading achievement. Second, third-grade classroom quality was a significant and direct predictor of third-grade children's engagement, but not reading achievement. Third, third-grade children's engagement significantly and positively contributed to their reading skills and first-grade children's reading achievement was a significant predictor of third-grade children's engagement.

Our first finding, that the indirect effect from classroom quality to children's reading achievement via children's engagement was significant, indicates that classrooms high in interactional quality may foster children's behavior engagement, which in turn predicts greater reading achievement. This finding extends recent findings by Ponitz et al. (2009) suggesting that the quality in teacher-child interactions and student participation in these interactions, defined as engagement, are likely central factors influencing children's academic gains. Our data further support the view that the quality of teacher-child interactions must be considered along with student engagement (Guthrie et al., 2001; Greenwood et al., 2002; Perry et al., 2002; Ponitz et al., 2009). As our data are correlational, however, we cannot infer a causal connection. Instead, we suggest that children's engagement is a "value-added" factor that helps us to understand the "intersection" between teachers' classroom instruction and children's achievement (e.g., reading achievement; Greenwood et al., 2002; Ponitz et al., 2009). 


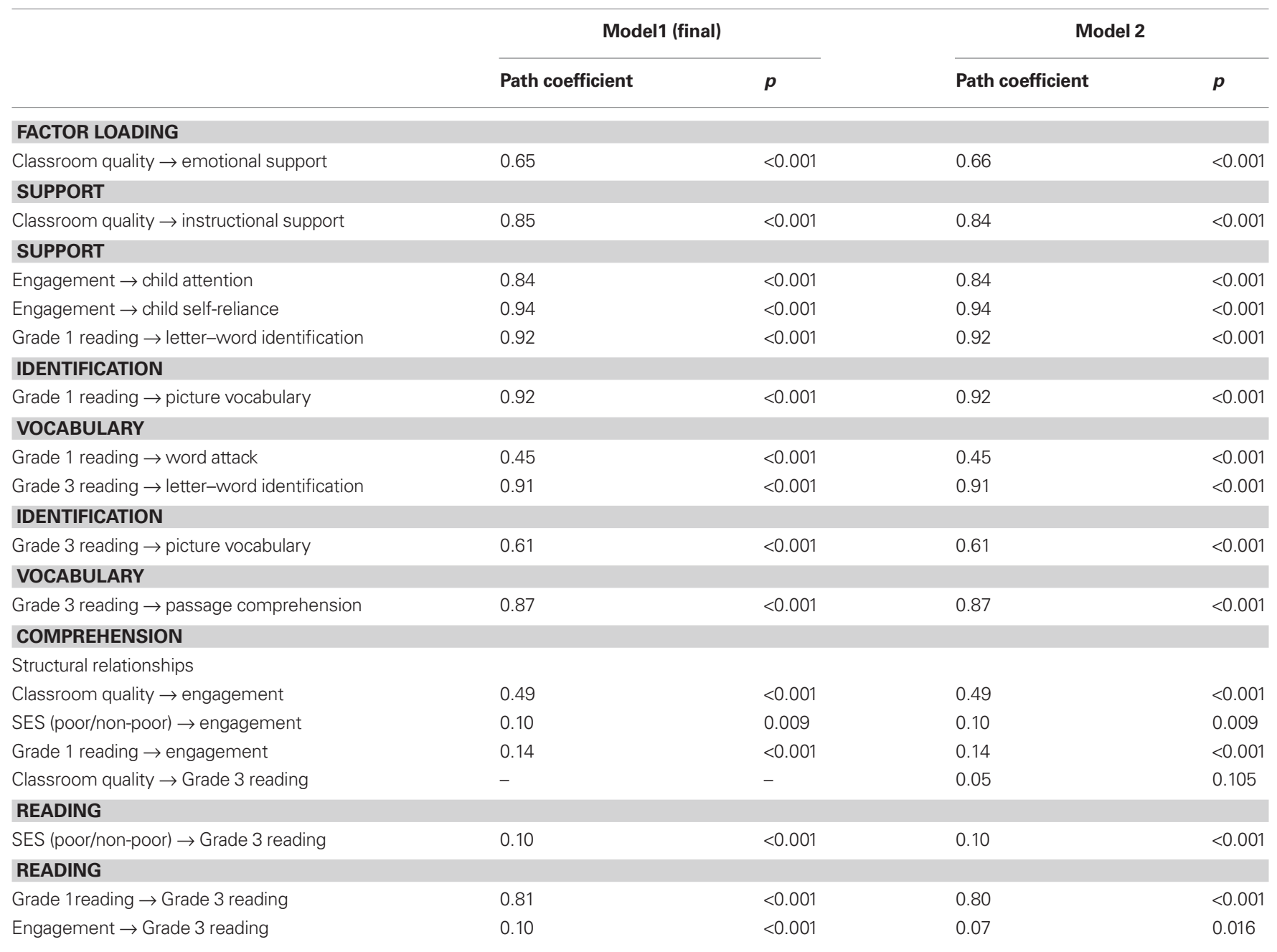

We must also point out that this significant indirect effect obtained from the present study has relevance to theories of ecological developmental model as well as practical implications concerning children's learning. Concerning the former, this finding supports the theoretical claim of ecological developmental model that proximal process such as child engagement has a direct influence upon child development (Bronfenbrenner and Morris, 2006). Moreover, the present finding also supports the argument that the nature of interconnections between process (child engagement), context (classroom quality), and children's reading skills tended to be interactive, rather than individual (Bronfenbrenner, 1979). Concerning the practical implications of this finding, given that classroom quality was associated with improved student reading achievement through increased level of child engagement, it is important to study more closely the specific features of classroom quality that influence children's engagement. Thus, we suggest that teachers can attempt to increase students' engagement in the classroom and expect that such engagement may improve student learning. By contrast, if students are not highly engaged, even though teachers provide high-quality instruction, such instruction may not provide a salient learning opportunity and hence not influence student achievement.
Our second finding was that classroom quality was a significant predictor of children's engagement, which adds to the rapidly accumulating evidence that classroom quality is critical to children's engagement (e.g., Ryan and Patrick, 2001; Hughes and Kwok, 2007). This finding also indicated that high-quality classrooms may provide many opportunities for rich interactions between teachers and students. Specifically, these classrooms provided warm emotional interactions and effective, thought-provoking activities. Such classroom environments are likely to increase children's interest and engagement in learning tasks. Warranting further discussion was that we found that the direct link between classroom quality and children's reading achievement was not significant. Although this may seem paradoxical, it is consistent with a previous study that demonstrated that the association between classroom quality and kindergarteners' reading achievement was not significant when children's engagement was included (Ponitz et al., 2009). Perhaps this finding further highlighted the importance of student engagement in explaining the association between classroom quality and children's achievement. The third major finding was that students' third-grade engagement emerged as a significant predictor of their reading achievement. This may 
reflect the fact that students who can be engaged in episodes of learning activities essentially demonstrate successful study behaviors and learn to read. Our finding is compatible with the previous findings suggesting that features of early behavior engagement were associated with reading achievement from kindergarten to sixth grade (McClelland et al., 2000, 2006). More importantly, the significant association between child engagement and reading skills also provides support for the social-interactionist theories that emphasizes engagement as crucial to literacy learning (Bruner, 1981). In light of these findings, we argue that emphasis on student engagement may be warranted. It is also important to note that we found a significant association between Grade 1 reading skills and Grade 3 engagement. This finding indicates that reciprocal associations between children's engagement and their reading achievement may be occurring. As our data is correlational and includes Grade 1 and Grade 3 children's reading achievement, much more evidence on the nature of this reciprocal connection is needed.

In interpreting our findings, it is worth noting that our data also demonstrate that children who have stronger reading skills in first grade are more likely to attend higher quality classrooms in third grade. This finding supports a possible mechanism for the Matthew effect (Stanovich, 1986). This is the observation that children with stronger reading skills early in their school career achieve increasingly higher skills whereas children with weaker skills show less reading skill gain (the rich get richer...). Our results indicate that children with stronger early literacy skills are more likely to experience higher quality classroom environments, which would lead to greater engagement and, hence stronger reading skills than children with weaker first-grade reading skills. Thus, the Matthew effect appears to influence the association between children's engagement and their achievement. Consistent with previous researchers (e.g., Stanovich, 1986; Shaywitz et al., 1995), our findings further support intervention programs that are designed and implemented with socially disadvantaged children.

\section{LIMITATIONS AND FUTURE DIRECTIONS}

A number of limitations and areas for future investigation warrant note. First, similar to any correlational study, we cannot assume that the observed relations among classroom quality, children's engagement, and children's reading achievement are causal in nature. In addition, our analysis did not test the reciprocity effects of classroom quality and children's engagement on children's reading skills. Future investigation should focus on experimental studies to identify any causal and reciprocity effects. Second, the results of this study are limited by children's engagement measures in that the metric used only assessed children's behavioral engagement. However, there are other types of children's engagement, namely cognitive engagement (e.g., strategy use, metacognition) and motivational engagement (e.g., interest, value, affect). Another necessary component to represent the multidimensional nature of children's engagement is disaffection, reflecting the core behaviors of disengagement such as lack of initiation or effort (Skinner et al., 2008). Given the importance of cognitive and motivational engagement and disaffection in student learning (Pintrich and Schrauben, 1992; Eccles et al., 1998; Skinner et al., 2008), future studies should broaden to include children's cognitive and motivational engagement and disaffection. Third, the measure of classroom quality in the current study was also potentially biased, in the sense that it used quality ratings of teacher-child interactions, based on classroom observation conducted at one point in time. Future investigation may employ multiple methods to capture classroom quality such as observation, self-reported survey, and quantitative analysis from videos.

Additionally, amounts, types, and quality of reading instruction were not included in the model. It is possible that both quality of the classroom environment and amounts and types of instruction both contribute, directly and indirectly, to children's reading achievement in third grade. There is accumulating evidence that appropriate and evidence-based reading achievement contributes to reading skill gains (NRP, 2000). Thus, research efforts designed to study types and quality of reading instruction that influence children's engagement and reading skills are important future lines of inquiry.

\section{IMPLICATION AND CONCLUSION}

The question of how best to teach children to read accurately and rapidly and with comprehension by the end of third-grade is one of the most important topics in the education literature. This study highlighted the importance of classroom quality and student engagement in promoting students' reading achievement. More importantly, we found that high-quality classroom instruction may improve children's engagement, which in turn promotes their reading achievement.

These findings provide an important consideration for administrators, researchers, and teachers. First, in order to ensure the highest level of students' reading gains, administrators and teachers should foster high-quality teacher interactions with children, including building warm relationships with individual children, providing discussions and activities to promote children's higher-order thinking skills, and extending students' learning. Second, given the importance of student engagement in influencing the association between classroom quality and student achievement, teachers should observe whether their students are highly engaged in learning activities. If students are not, teachers can attune their instruction or activities to promote student engagement (Ponitz et al., 2009). Third, educational researchers should develop the effective approaches for teachers to improve student engagement. For example, effective practices include maximizing the opportunities for social interactions during small-group activity (Blatchford et al., 2002), providing clear behavioral or task expectations (Matheson and Shriver, 2005), and supporting children's misbehavior proactively (Ponitz et al., 2009).

To sum up, research has supported varied routes toward supporting children's reading achievement. Our study suggested that efforts focused on promoting both classroom quality and children's engagement could be important for creating a positive learning environment where children can be engaged in activities and achieve more. 


\section{REFERENCES}

Adams, J. W., and Snowling, M. J. (2001). Executive function and reading impairments in children reported by their teachers as "hyperactive." $B r$. J. Dev. Psychol. 19, 293-306.

Arbuckle, J. L. (2006). AMOS 7.0. User Guide. Chicago: SmallWaters Corporation.

Assor, A., Kaplan, H., and Roth, G. (2002). Choice is good, but relevance is excellent: autonomy-enhanced and suppressing teacher behaviors predicting students' engagement in schoolwork. Br. J. Educ. Psychol. 72, 261-278.

Bangert-Drowns, R. L., and Pyke, C. (2001). A taxonomy of student engagement with educational software: an exploration of literate thinking with electronic text. J. Educ. Comput. Res. 24, 213-234.

Birch, S. H., and Ladd, G. W. (1997). The teacher-child relationship and children's early school adjustment. J. Sch. Psychol. 35, 61-79.

Blatchford, P., Moriarty, V., Edmonds, S., and Martin, C.A. (2002). Relationships between class size and teaching: a multimethod analysis of English infant schools. Am. Educ. Res. J. 39, 101-132.

Bronfenbrenner, U. (1979). The Ecology of Human Development: Experiments by Nature and Design. Cambridge, MA: Harvard University Press.

Bronfenbrenner, U., and Morris, P. A. (2006). "The bio-ecological model of human development," in Handbook of Child Psychology: Theoretical Models of Human Development, 6th Edn, Vol. 1, eds R. M. Lerner and W. Damon (Hoboken, NJ: Wiley and Sons), 793-828.

Brown, W., and Cudeck, R. (1993). "Alternative ways of assessing model fit," in Testing Structural Equation Models, eds K. A. Bollen and J. S. Long (Newbury Park, CA: Sage), 247-261.

Bruner, J. (1981). The social context of language acquisition. Lang. Commun. $1,155-178$.

Campbell,J.R., Voelkl, K.E., and Donahue, P. L. (1997). NAEP 1996 Trends in Academic Progress. Washington, DC: National Center for Education Statistics.

Connell, J. P., and Wellborn, J. G. (1991). "Competence, autonomy, and relatedness: a motivational analysis of self-system processes," in Minnesota Symposia on Child Psychology, Vol. 23, R. Gunnar and L. A. Sroufe (Hillsdale, NJ: Erlbaum), 43-77.

Connor, C. M., Son, S. H., Hindman, A. H., and Morrison, F. J. (2005). Teacher qualifications, classroom practices, family characteristics, and preschool experience: complex effects on first graders' vocabulary and early reading outcomes. J. Sch. Psychol. 43, 343-375.

Deci, E. L., and Ryan, R. M. (1985). Intrinsic Motivation and Self-Determination in Human Behavior. New York: Plenum.

Eccles, J. S. (1993). "School and family effects on the ontogeny of children's interests, self-perceptions, and activity choices," in Nebraska Symposium on Motivation, Vol. 40, Developmental Perspectives on Motivation, ed. J. Jacobs (Lincoln: University of Nebraska Press), 145-208

Eccles, J. S., Roeser, R., Vida, M., Fredricks, J., and Wigfield, A. (2006). "Motivational and achievement pathways through middle childhood," in Child Psychology: A Handbook of Contemporary Issues, eds L. Balter and C. S. Tamis-LeMonda (New York, NY: Psychology Press), 325-355.

Eccles, J. S., Wigfield, A., and Schiefele, U. (1998). "Motivation to succeed," in Handbook of Child Psychology, Vol. 3, Social, Emotional and Personality Development, 5 th Edn, eds W. Damon and N. Eisenberg (New York: Wiley), 1017-1095.

Fredericks, J. A., Blumenfeld, P. C., and Paris, A. H. (2004). School engagement: potential of the concept, state of the evidence. Rev. Educ. Res. 74 59-109.

Greenwood, C. R., Horton, B. T., and Utley, C. A. (2002). Academic engagement: current perspectives on research and practice. School Psych. Rev. 31, 328-349.

Gregory, A., and Weinstein, R. S. (2004). Connection and regulation at home and in school: predicting growth in achievement for adolescents. J. Adolesc. Res. 19, 405-427.

Guthrie, J. T. (1996). Educational contexts for engagement in literacy. Read. Teach. 46, 432-445.

Guthrie, J. T., Schafer, W. D., and Huang, C. W. (2001). Benefits of opportunity to read and balanced instruction on the NAEP. J. Educ. Res. 94, 145-162.

Guthrie, J. T., and Wigfield, A. (2000).

"Engagement and motivation in reading," in Handbook of Reading Research, Vol. III, eds M. Kamil, R. Barr, P. Mosenthal, and P. D. Pearson (New York: Longman), 4037425.

Hamre, B. K., and Pianta, R. C. (2005). Can instructional and emotional support in the first-grade classroom make a difference for children at risk of school failure? Child Dev. 76, 949-967.

Hamre, B. K., and Pianta, R. C. (2007) "Learning opportunities in preschool and early elementary classrooms," in School Readiness and the Transition to Kindergarten in the Era of
Accountability, eds R. Pianta, M. Cox, and K. Snow (Baltimore: Brookes), 49-84.

Hu, L., and Bentler, P. M. (1999). Cutoff criteria for fit indexes in covariance structure analysis: conventional criteria versus new alternatives. Struct. Equ. Modeling 6, 1-55.

Hughes, J., and Kwok, O. (2007). Influence of student-teacher and parent-teacher relationships on lower achieving readers' engagement and achievement in the primary grades. J. Educ. Psychol. 99, 39-51.

Justice, L. M., Mashburn, A. J., Hamre, B. K., and Pianta, R. C. (2008). Quality of language and literacy instruction in preschool classrooms serving at-risk pupils. Early Child. Res. Q. 23, 51-68.

Kumar, D. D. (1991). A meta-analysis of the relationship between science instruction and student engagement. Educ. Rev. 43, 49-61.

Linnenbrink, E. A., and Pintrich, P. R. (2003). The role of self-efficacy beliefs in student engagement and learning in the classroom. Read. Writ. Q. 19, 119-137.

Little, M., and Kobak, R. (2003). Emotional security with teachers and children's stress reactivity: a comparison of special-education and regulareducation classrooms. J. Clin. Child Adolesc. Psychol. 32, 127-138.

MacKinnon, D. P., Lockwood, C. M. Hoffman, J.M., West, S. G., and Sheets, V. (2002). A comparison of methods to test mediation and other intervening variable effects. Psychol. Methods 7, 83-104.

Makin, L. (2003). "Creating positive literacy learning environments in early childhood," in Handbook of Early Childhood Literacy, eds N. Hall, J. Larsonand and J. Marsh (Thousand Oaks, CA: Sage), 327-337.

Marks, H. M. (2000). Student engagement in instructional activity: patterns in the elementary, middle, and high school years. Am. Educ. Res. J. 37, 153-184.

Marsh, H. M. (1994). Using the National Longitudinal Study of 1988 to evaluate theoretical models of self-concept: the self description questionnaire. J. Educ. Psychol. 86, 439-456.

Mashburn,A. J., Pianta, R. C., Barbarin, O. A., Bryant, D., Hamre, B. K., Downer J. T., Burchinal, M., and Early, D. M. (2008). Measures of classroom quality in prekindergarten and children's development of academic, language, and social skills. Child Dev. 79, 732-749.

Matheson, A. S., and Shriver, M. D. (2005) Training teachers to give effective comments: effects on student compliance and academic behaviors. School Psych Rev. 34, 202-219.

Maughan, B., and Carroll, J. (2006). Literacy and mental disorders. Curr. Opin. Psychiatry 19, 350-354.

McClelland, M. M., Acock, A. C., and Morrison, F. J. (2006). The impact of kindergarten learning-related skills on academic trajectories at the end of elementary school. Early Child. Res. Q. 21, 471-490.

McClelland, M. M., Morrison, F. J., and Holmes, D. L. (2000). Children at risk for early academic problems: the role of learning-related social skills. Early Child. Res. Q. 15, 307-329.

Meehan, B. T., Hughes, J. N., and Cavell, T.A. (2003). Teacher-student relationships as compensatory resources for aggressive children. Child Dev. 74, 1145-1157.

National Assessment for Education Progress. (2005). The Nation's Report Card. Washington, DC: National Center for Education Statistics.

National Assessment of Educational Progress (NAEP). (2007). National Assessment of Educational Progress: The Nations Report Card [Electronic Version]. Available at: http://nces. ed.gov/nationsreportcard/ [retrieved January 2010].

Newmann, F. M. (ed.). (1992). Student Engagement and Achievement in American Secondary Schools. New York: Teachers College Press.

NICHD-ECCRN. (2000). The relation of child care to cognitive and language development. Child Dev.71,960-980.

NICHD-ECCRN. (2002). Child-care structure - process - outcome: direct and indirect effects of child-care quality on young children's development. Psychol. Sci. 13, 199-206.

NICHD-ECCRN. (2003). Social functioning in first grade: associations with earlier home and child care predictors and with current classroom experiences. Child Dev. 74, 1639-1662.

NRP. (2000). National Reading Panel report: Teaching Children to Read: An Evidence-Based Assessment of the Scientific Research Literature on Reading and its Implications for Reading Instruction (No. NIH Pub. 00-4769). Washington, DC: U.S. Department of Health and Human Services, Public Health Service, National Institutes of Health, Nationa Institute of Child Health and Human Development. (Document Number) Perry, N. E., VanderKamp, K. O., Mercer, L. K., and Nordby, C. J. (2002). Investigating teacher-child interactions that foster self-regulated learning. Educ. Psychol. 37, 5-15. 
Peterson, P. L., Swing, S. R., Stark, K. D., and Waas, G. A. (1984). Students' cognitions and time on task during mathematics instruction. Am. Educ. J. 21, 487-515.

Petrill, S. A., Deater-Deckard, K., Thompson, L. A., Schatschneider, C., DeThorne, L. S., and Vandenbergh, D. J. (2007). Longitudinal genetic analysis of early reading: the Western Reserve Reading Project. Read. Writ. 20, 127-146.

Pianta, R. C., Belsky, J., Vandergrift, N., Houts, R., and Morrison, F. J. (2008a). Classroom effects on children's achievement trajectories in elementary school. Am. Educ. Res. J. 45, 365-397.

Pianta, R. C., La Paro, K. M., and Hamre, B. K. (2008b). Classroom Assessment Scoring System (CLASS). Baltimore: Paul H. Brookes.

Pianta, R. C., and Hamre, B. K. (2009). Classroom processes and positive youth development: conceptualizing, measuring, and improving the capacity of interactions between teachers and students. New Dir. Youth Dev. 121, 33-46.

Pianta, R. C., La Paro, K. M., Payne, C., Cox, M. J., and Bradley, R. (2002). The relation of kindergarten classroom environment to teacher, family, and school characteristics and child outcomes. Elem. Sch. J. 102, 225-238.

Pintrich, P. R., and Schrauben, B. (1992). "Students' motivational beliefs and their cognitive engagement in classroom tasks," in Studen Perceptions in the Classroom: Causes and Consequences, eds D. Schunk and J. Meece (Hillsdael, NJ: Erlbaum), 149-183.
Ponitz, C., Rimm-Kaufman, S. E. Grimm, K. J., and Curby, T.W. (2009). Kindergarten classroom quality, behavioral engagement, and reading achievement. School Psych. Rev. 38, 102-120.

Preacher, K. J., and Leonardelli, G. J. (2001). Calculation for the Sobel Test: An Interactive Calculation Tool for Mediation Tests [Computer software]. Available at: http://www.quantpsy.org

Rayner, K., Foorman, B. R., Perfetti, C. A., Pesetsky, D., and Seidenberg, M S. (2001). How psychological science informs the teaching of reading. Psychol. Sci. Public Int. 2, 31-74.

Ridley, S. M., McWilliam, R.A., and Oates, C. S. (2000). Observed engagement as an indicator of child care program quality. Early Educ. Dev. 11, 133-146.

Rimm-Kaufman, S. E., Early, D. M., Cox, M. J., Saluja, G., Pianta, R. C., Bradley, R. H., and Payne, C. (2002). Early behavioral attributes and teachers' sensitivity as predictors of competent behavior in the kindergarten classroom. Appl. Dev. Psychol. 23, 451-470.

Rivik, S. G., Hanushek, E. A., and Kain, J. F. (2000). Teachers, Schools, and Academic Achievement. Dallas, TX: University of Texas at Dallas, Cecil and Ida Green Center for the Study of Science and Society.

Roeser, R. W., Eccles, J.S., and Sameroff, A. J. (2000). School as a context of early adolescents' academic and socialemotional development: a summary of research findings. Elem. Sch. J. 100, 443-471.

Ryan, A., and Patrick, H. (2001). The classroom social environment and changes in adolescents' motivation and engagement during middle school. Am. Educ. Res. J. 38, 437-460.
Shaywitz, B. A., Holford, T. R., Holahan, J. M., Fletcher, J. M., Steubing, K. K., Francis, D. J., and Shaywitz, S. E. (1995). A Matthew effect for IQ but not for reading: results from a longitudinal study. Read. Res. Q. 30, 894-908.

Singh, K., Granville, M., and Dika, S. (2002). Mathematics and science achievement: effects of motivation, interest, and academic engagement. J. Educ. Res. 95, 323-332.

Skinner, E. A., Kindermann, T. A., and Furrer, C. J. (2008).A motivational perspective on engagement and disaffection. Educ. Psychol. Meas. 69, 493-525.

Skinner, E. A., Wellborn, J. G., and Connell, J. P. (1990). What it takes to do well in school and whether I've got it: the role of perceived control in children's engagement and school achievement. J. Educ. Psychol. 8, 22-32.

Snow, C. E. (2001). Knowing what we know: children, teachers and researchers. Educ. Res. 30, 3-9.

Snow, C.E., Burns, M., and Griffin, P. (eds) (1998). Preventing Reading Difficulties in Young Children. Washington, DC: National Academy Press.

Stanovich, K. E. (1986). Matthew effects in reading: some consequences of individual differences in the acquisition of literacy. Read. Res. Q. 21, 360-407.

Taylor, N. E., Blum, I. H., and Logsdon, D. M. (1986). The development of written language awareness: environmental aspects and program characteristics. Read. Res. Q. 21, 132-149.

Wasson, B. B., Beare, P. L., and Wasson, J. B. (1990). Classroom behavior of good and poor readers. J. Educ. Res. 83, 162-165.

Wentzel, K. R. (1999). Social-motivational processes and interpersonal relationships: implications for understanding students' academic success. J. Educ. Psychol. 91, 76-97.

Wigfield, A., Guthrie, J. T., Perencevich, K. C., Taboada, A., Klauda, S. L., McRae, A., and Barbosa, P. (2008). Role of reading engagement in mediating effects of reading comprehension instruction on reading outcomes. Psychol. Sch. 45, 432-445.

Woodcock, R. W., and Mather, N. (2001). Woodcock Johnson III Tests of Achievement: Examiner's Manual. Itasca, IL: Riverside.

Woodcock, R. W., and Johnson, M. B. (eds).(1989/1990). Woodcock-Johnson Tests of Achievement, (Revised Edn.). Itasca, IL: Riverside Publishing Co.

Conflict of Interest Statement: The authors declare that the research was conducted in the absence of any commercial or financial relationships that could be construed as a potential conflict of interest.

Received: 04 October 2010; accepted: 23 June 2011; published online: 07 July 2011. Citation: Guo Y, Connor CM, Tompkins V and Morrison FJ (2011) Classroom quality and student engagement: contributions to third-grade reading skills. Front. Psychology 2:157. doi: 10.3389/fpsyg.2011.00157 This article was submitted to Frontiers in Educational Psychology, a specialty of Frontiers in Psychology.

Copyright $(2011$ Guo, Connor, Tompkins and Morrison. This is an open-access article subject to a non-exclusive license between the authors and Frontiers Media SA, which permits use, distribution and reproduction in other forums, provided the original authors and source are credited and other Frontiers conditions are complied with. 